\title{
TREATMENT OF ULNAR NERVE PALSY AT THE ELBOW WITH A NIGHT SPLINT
}

P. SEROR

From the Laboratoire d'Electromyographie, Paris, France
Twenty-two patients with ulnar nerve palsy at the elbow, confirmed by electromyography, were treated by a night splint which prevented flexion of the elbow beyond $60^{\circ}$. The splint was worn all night regularly for at least six months. At a mean follow-up of 11.3 months, 17 patients had clinical and electromyographic assessment and five were contacted by telephone.

There was improvement in the symptoms in every patient, including three who had failed to respond to surgical decompression. There was electromyographic improvement in 16 of the 17 patients re-examined at followup. The mean improvement in motor nerve conduction velocity was $6.5 \mathrm{~m} / \mathrm{s}$ and in sensory nerve conduction velocity $9.5 \mathrm{~m} / \mathrm{s}$. The efficacy of this treatment suggests that nocturnal elbow flexion is an important cause of ulnar nerve lesions at the elbow.

J Bone Joint Surg [ Br] 1993; 75-B : 322-7.

Received 5 February 1992; Accepted 16 June 1992

The treatment of ulnar nerve palsy at the elbow is contentious. Infiltration with corticosteroid is often used, but its efficacy is very uncertain and at least five different surgical techniques have been described (Dellon 1989). The results are much less spectacular than those of decompression of the median nerve in the carpal tunnel, which suggests that narrowing of the cubital tunnel is not the only element responsible for the lesion.

As early as 1899 , Gowers suggested that prolonged flexion of the elbow could itself induce ulnar nerve palsy, but subsequently this finding appears to have been largely forgotten. The description by Osborne in 1957 of the cubital tunnel as the anatomical feature responsible for nerve palsy placed ulnar nerve lesions at the elbow in the category of tunnel syndromes, and implied the need for the therapeutic methods usually employed for such

P. Seror, MD

Laboratoire d'Electromyographie, 148 Avenue Parmentier, 75011 Paris, France.

(C)1993 British Editorial Society of Bone and Joint Surgery $0301-620 X / 93 / 2484 \$ 2.00$ lesions. My experience is that patients with ulnar neuropathy at the elbow regularly suffer from symptoms after sleeping with the elbow flexed (Seror 1992).

The results are now reported of the use of a night splint to limit elbow flexion in 22 patients with ulnar nerve palsy at the elbow.

\section{PATIENTS AND METHODS}

Twenty-two consecutive patients, 12 men and 10 women, were studied. They had presented with clinical symptoms and electromyography (EMG) had demonstrated ulnar nerve lesions at the elbow. Their mean age was 52 years (39 to 81). The symptoms were in the right arm in 15 and the left in seven, but EMG showed bilateral signs in 14 . The mean duration of symptoms was 8.3 months $(0.5$ to 24).

Sixteen of the patients were classified as having idiopathic symptoms, and three of these had undergone unsuccessful surgical decompressions. Five cases had developed after a general anaesthetic and there was one case of tardy ulnar palsy after an old fracture.

Clinical signs and symptoms. The patients had subjective symptoms or objective sensory signs of atrophy of the ulnar intrinsic muscles of the hand or both. Three types of paraesthesia were experienced: intermittent tingling at night or in the morning on waking, which rapidly resolved after moving the limb; permanent paraesthesiae; or permanent paraesthesiae which were worse at night or in the morning on waking, a combination of the first two types.

EMG signs. In every case, EMG confirmed the ulnar nerve lesion at the elbow and excluded a lesion at the wrist or in the brachial plexus or a polyneuropathy. Two patients also showed slight signs of a median nerve lesion at the wrist, but the ulnar nerve lesion was the cause of the symptoms. This was demonstrated when injection of corticosteroid (Cortivazol; Roussel, Paris) into the carpal tunnel was ineffective in both cases and immobilisation of the elbow rapidly relieved the symptoms.

In all cases the ulnar nerve lesion at the elbow was confirmed by an alteration in the motor and sensory nerve conduction velocities. The nerve conduction velocity (NCV) at the elbow was always recorded separately from that in the forearm, by means of a focal 
study of the elbow region over a distance of $10 \mathrm{~cm}(6 \mathrm{~cm}$ below and $4 \mathrm{~cm}$ above the medial epicondyle with the elbow flexed to $35^{\circ}$ ). The NCV was considered to be pathological when it was less than $45 \mathrm{~m} / \mathrm{sec}$ and $20 \%$ less than the motor nerve conduction velocity in the forearm or the sensory nerve conduction velocity at the wrist.
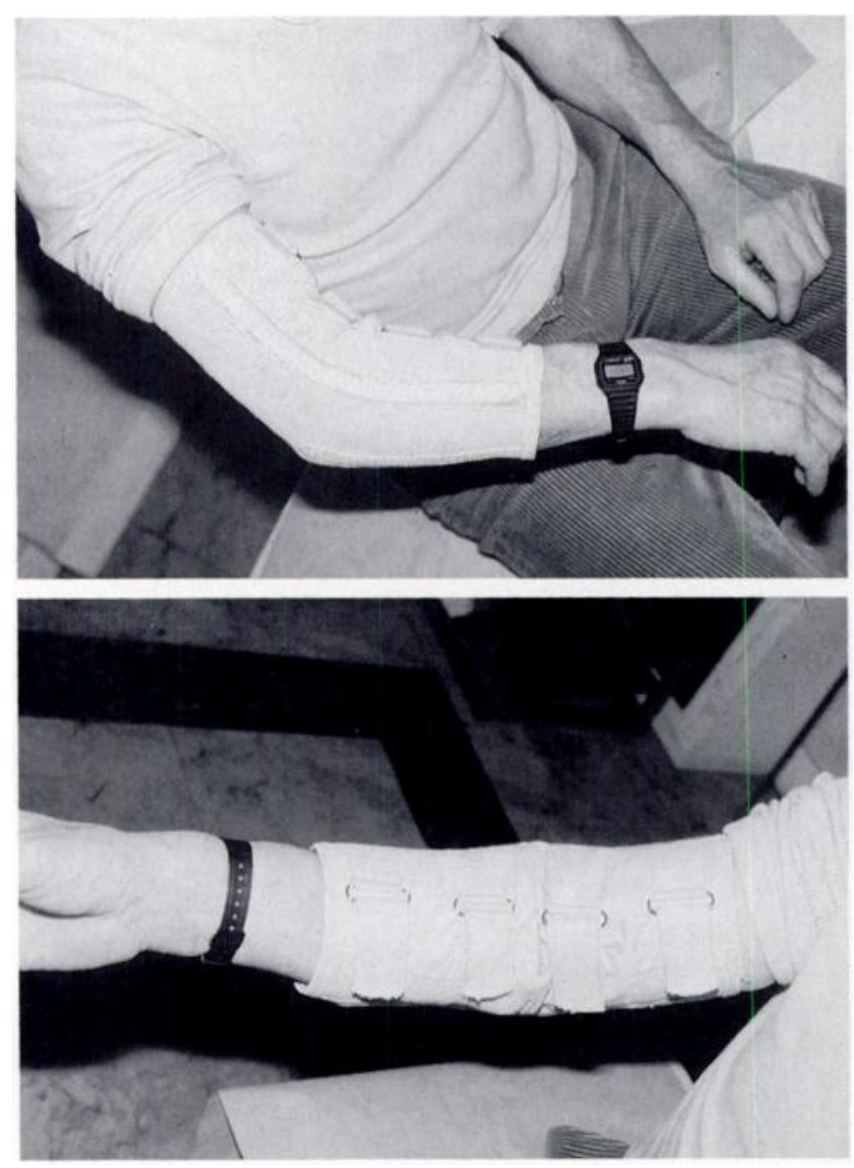

Fig. 1

The night splint limits elbow movements to between $15^{\circ}$ and $60^{\circ}$ flexion.

Treatment. Treatment was by a splint (Fig. 1) which limited elbow movements to between $15^{\circ}$ and $60^{\circ}$ flexion but allowed unrestricted pronation and supination. The patient was advised to wear the splint all night and every night for six months and thereafter to use it as regularly as possible. In most cases, its use was continued intermittently after six months. In addition, patients were advised not to rest the elbow on a hard surface and to avoid prolonged flexion of the joint while working.

Whenever possible, each patient was clinically reviewed 15 days after application of the splint. The clinical and EMG examinations were repeated at two months and then at six months or later.

Evaluation. The patients were questioned at each visit concerning the regularity of use of the splint. The clinical evaluation criteria were: paraesthesia of the little and ring fingers, whether nocturnal, intermittent or permanent; Tinel's sign on palpation at the epitrochlear groove; evaluation of pain according to a visual analogue scale; muscle wasting; muscle strength; sensory testing using Weber's static two-part discrimination test and the Semmes-Weinstein test (Omer 1979); and the overall improvement score evaluated at each visit by the patient and by the physician (Table I).

Table I. Signs and symptoms of ulnar nerve palsy before and after treatment. Mean values are given for sensory tests, pain, muscle strength and wasting

\begin{tabular}{lll}
\hline & $\begin{array}{l}\text { Before } \\
\text { treatment }\end{array}$ & $\begin{array}{l}\text { At final } \\
\text { review }\end{array}$ \\
\hline $\begin{array}{l}\text { Paraesthesiae in little and ring fingers } \\
\text { Nocturnal or on waking }\end{array}$ & $\begin{array}{c}100 \% \\
73 \%\end{array}$ & $\begin{array}{c}45 \% \\
4 \%\end{array}$ \\
Permanent & $77 \%$ & $31 \%$ \\
STPD (normal <6) & 6.4 & 5.8 \\
Semmes-Weinstein test (normal =1) & 2.0 & 1.3 \\
Pain (visual analogue scale 0 to 10) & 3.1 & 0.2 \\
Muscle strength (normal) & $55 \%$ & $87 \%$ \\
Muscle wasting (present) & 4 & 3 \\
Tinel's sign (present) & 8 & 6 \\
Overall improvement score & $0 \%$ & $87 \%$ \\
\hline
\end{tabular}

- static two-point discrimination test

The EMG evaluation criteria were: the motor NCV at the elbow; the orthodromic sensory NCV at the elbow; the amplitude of the sensory action potential (SAP) above the elbow; the amplitude of the SAP at the wrist; the detection of motor denervation in the first interosseous muscle or adductor digiti minimi; and the distal motor latency (DML) and sensory NCV at the wrist (Table II).

\section{RESULTS}

Seventeen patients were followed up for a mean 11.3 months (4 to 30 ) after adoption of the night splint. Five patients were contacted by telephone at a mean of 12 months.

Clinical data. The clinical findings before treatment and at last review are given in Table I. Of the patients reviewed, in eight symptoms had disappeared, in five there was $80 \%$ to $90 \%$ relief and in four $50 \%$ to $70 \%$ relief. The five patients who had not been reviewed all declared themselves to be cured.

Nocturnal paraesthesiae (present in 16 patients) always improved first. Permanent paraesthesiae (present in 17 patients) improved more gradually with time. Pain was rarely intense and was felt in the forearm and hand as well as in the region of the medial epicondyle. The initial mean score for pain was 3.1 which had decreased to 0.2 by the end of treatment.

Overall, the muscle strength was unchanged, since in more than half of the patients, it had been normal at first. When it had been initially markedly decreased, 
Table II. Electromyographic data (mean \pm SD) before ( 22 cases) and after treatment (17 cases)

\begin{tabular}{|c|c|c|c|}
\hline & Before treatment & $\begin{array}{l}\text { Change } \\
\text { at review }\end{array}$ & p value \\
\hline Motor conduction velocity $(\mathrm{m} / \mathrm{s})$ & $32.2 \pm 10.7$ & $+6.5 \pm 5.2$ & $<10^{-8}$ \\
\hline Sensory conduction velocity $(\mathrm{m} / \mathrm{s})$ & $36.2 \pm 6.5$ & $+9.5 \pm 6.7$ & $<10^{-9}$ \\
\hline $\begin{array}{l}\text { Sensory action potential }(\mu \mathrm{V}) \\
\text { Elbow } \\
\text { Wrist }\end{array}$ & $\begin{array}{l}0.98 \pm 1.25 \\
8.8 \pm 6.0\end{array}$ & $\begin{array}{l}+1.0 \pm 1.21 \\
+4.6 \pm 8.3\end{array}$ & $\begin{array}{l}<10^{-4} \\
<0.02\end{array}$ \\
\hline Distal motor latency at wrist $(\mathrm{m} / \mathrm{s})$ & $3.4(2.5$ to 7.9$)$ & $-0.35 \pm 0.42$ & \\
\hline Sensory conduction velocity at wrist $(\mathrm{m} / \mathrm{s})$ & $53.6 \pm 9.7$ & $+3.2 \pm 2.2$ & \\
\hline $\begin{array}{l}\text { Denervation* } \\
\text { Interference pattern } \\
\text { Reduced interference pattern } \\
\text { Very reduced interference pattern } \\
\text { Single potential }\end{array}$ & $\begin{array}{l}4 \\
3 \\
5 \\
5\end{array}$ & $\begin{array}{ll}+2 & \\
+4 & -1 \\
+3 & -4 \\
-4 & \end{array}$ & \\
\hline
\end{tabular}

* the number of patients showing each pattern before treatment, and the changes of pattern after treatment

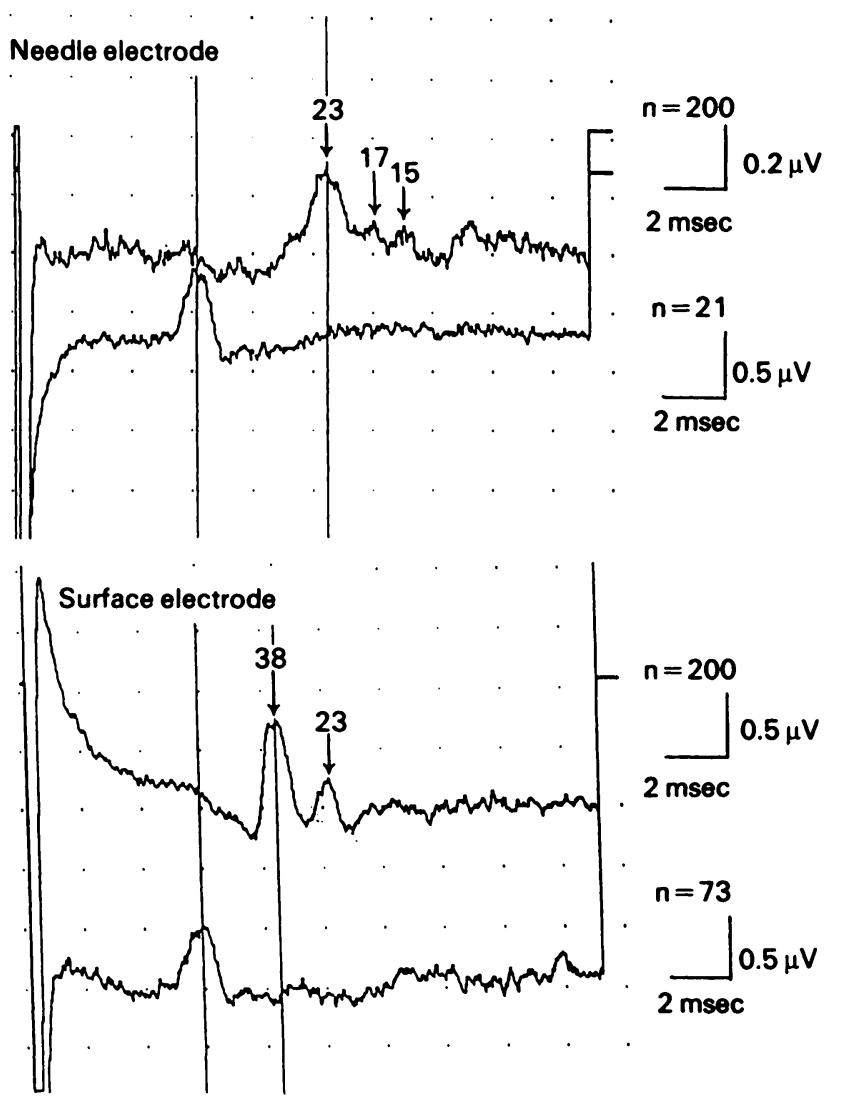

Fig. 2

The upper traces are before treatment and the lower traces two months after starting treatment. There is an improvement of the sensory conduction velocity at the elbow from 23 to $38 \mathrm{~m} / \mathrm{s}$. There is also an increase in amplitude $(0.3 \mu \mathrm{V}$ to $>1 \mu \mathrm{V})$ and a resynchronisation of the sensory action potential. At follow-up, surface electrode recording was possible, because of the higher amplitude of sensory action potential than at initial testing by needle recording.
B
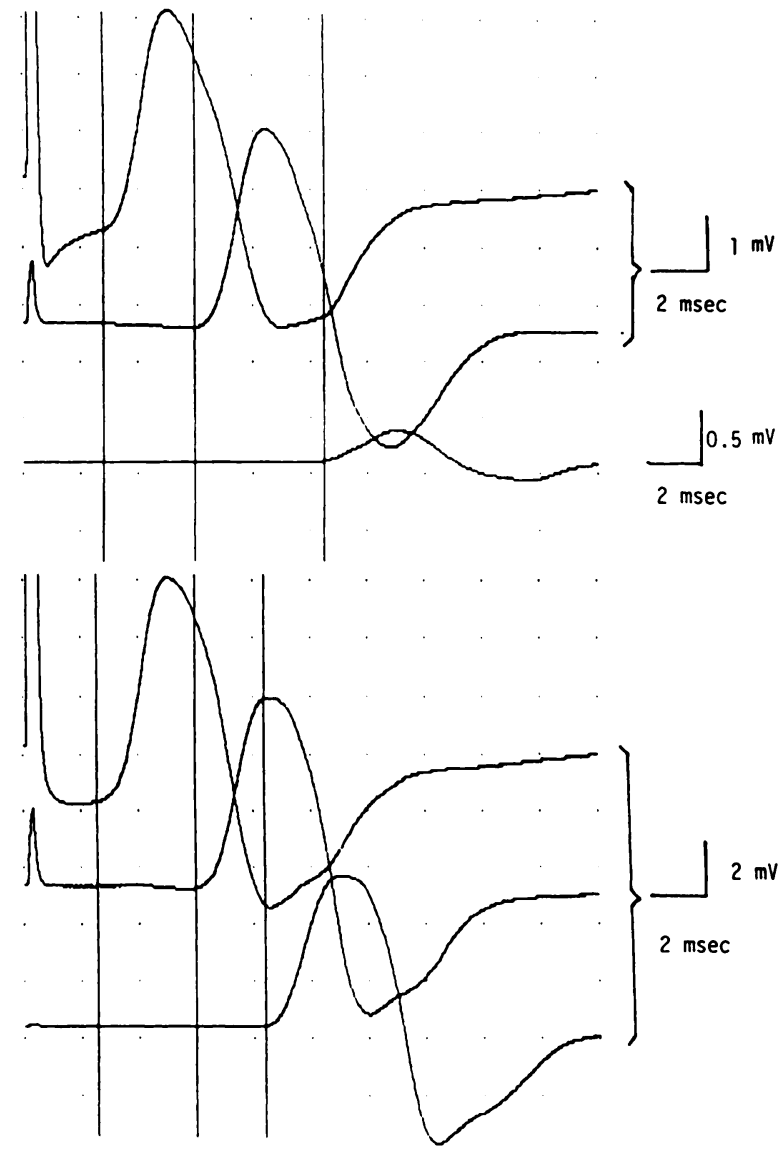

Fig. 3

Same case as in Figure 2. The upper traces are before treatment and the lower traces are two months after treatment. There is improvemen of the motor conduction velocity at the elbow (22 to $>42 \mathrm{~m} / \mathrm{s})$ and almost complete resolution of the motor conduction block (from $95 \%$ to $20 \%$ ). A = wrist; $\mathrm{B}=$ below elbow; $\mathrm{C}=$ above elbow. 
however, there was an improvement. In one patient, muscle strength which at first was much reduced was restored to normal after 15 days, probably due to resolution of a very severe motor conduction block with resynchronisation of the SAP (Figs 2,3 ).

Muscle wasting, which was initially present in only four patients, persisted in three at follow-up. The frequency of Tinel's sign was not significantly diminished, decreasing from $36 \%$ to $27 \%$ of cases at the end of the study.

Weber's test was abnormal in only six patients initially and did not significantly alter. The SemmesWeinstein test appeared to be slightly more sensitive with improvement in 10 of the 15 patients examined with a mean decrease from 2 to 1.3.

EMG data. Initial EMG data were available for all 22 patients, but only 17 were examined after treatment. The data before and after treatment are given in Table II.

The mean motor NCV at the elbow was initially $32.2 \mathrm{~m} / \mathrm{s}$ and improved by a mean of $6.5 \mathrm{~m} / \mathrm{s}$ (Student's $t$ test $=5.9, \mathrm{p}<10^{-8} ;$ Fig. $\left.4 \mathrm{a}\right)$.

The mean sensory NCV at the elbow was initially $36.2 \mathrm{~m} / \mathrm{s}$, but it could not be recorded in the most severe cases in which the sensory potential was less than $0.2 \mu \mathrm{V}$. It was improved by a mean of $9.5 \mathrm{~m} / \mathrm{s}$ (Student's $t$-test $=$ $6.8, \mathrm{p}<10^{-9}$; Fig. 4b).

The SAP at the elbow always had a low initial amplitude with a mean of $0.98 \mu \mathrm{V}$. It was virtually doubled after treatment with a mean gain of $1.00 \mu \mathrm{V}$ (Student's $t$-test $=3.8, \mathrm{p}<10^{-4}$ ). The SAP at the wrist is a good indicator of the axonal reserve of the nerve beyond the compression; it was initially decreased to $8.8 \mu \mathrm{V}$ (normal: $22 \mu \mathrm{V}$ ) and was subsequently increased by an average of $4.6 \mu \mathrm{V}$ (Student's $t$-test $=2.6, \mathrm{p}<0.02$ ).

Motor denervation, initially normal in four patients, remained unchanged in eight and was improved in nine. Tests of nerve conduction at the wrist showed only slight variations.

Compliance with treatment. Of the 22 patients, 14 regularly complied with treatment during the first six months. Thereafter four stopped treatment completely without recurrence and six developed a partial recurrence which responded to the reintroduction of treatment. The one patient with tardy ulnar palsy developed a complete recurrence, and later agreed to undergo surgery.

\section{DISCUSSION}

The pathophysiology of ulnar nerve palsy at the elbow is less well understood than that of carpal tunnel syndrome. Although the ulnar nerve certainly lies in an inextensible osseofibrous tunnel, it does not share the tunnel with tendons, and tenosynovitis cannot therefore reduce the space occupied by the nerve. Moreover, opening up the osteofibrous tunnel does not always provide the expected therapeutic result (Thomsen 1977; Chaise et al 1983; Dellon 1989). Some authors have tried to modify the bed

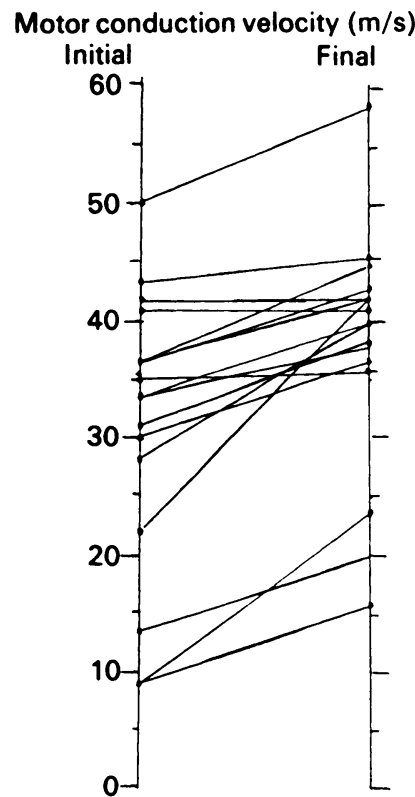

Fig. $4 a$
Sensory conduction velocity $(\mathrm{m} / \mathrm{s})$

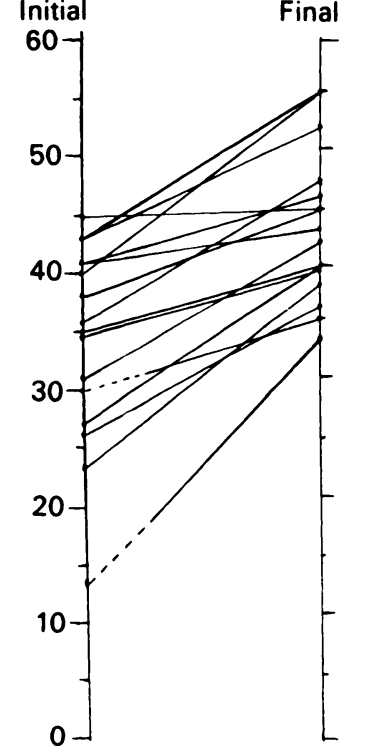

Fig. $4 b$
Figure 4a - Improvement in motor conduction velocity of the ulnar nerve at the elbow in 17 patients after treatment by the splint. Figure 4b - Improvement in orthodromic sensory conduction velocity (SCV) in 17 cases after treatment by the splint. The initial SCV was not obtained in four patients (see text) but was recorded in two of these at final follow-up. In these patients the initial conduction velocity, shown by a broken line, is the MCV.

of the ulnar nerve by enlarging the epitrochlear groove (de la Caffinière and Bex 1983; Dellon 1989; Heithoff et al 1990) or by changing the course of the nerve by anterior transposition (Lugnegard, Walheim and Wennberg 1977; Sindou et al 1982; Mansat et al 1984). Dellon (1989) recently analysed the results of five surgical techniques on the basis of 50 papers describing a total of more than 2000 patients and concluded that there were no sound criteria for choosing between them.

This study is based on the hypothesis that the ulnar nerve is subject to compression during elbow flexion, and that lesions can be caused by this, particularly during sleep when the lowered level of consciousness allows prolonged maintenance of harmful positions. During the day, nociceptive reflexes cause the harmful position to be altered before the development of a nerve lesion.

The fact that the cubital tunnel is narrower in some positions than in others has been known since the anatomical studies of Osborne (1957), Vanderpool et al (1968), and Apfelberg and Larson (1973).

Macnicol (1980) studied the pressures exerted on the nerve in various degrees of flexion of the elbow, and reported values of about $5 \mathrm{mmHg}$ in extension with no major increase up to $90^{\circ}$ flexion. Above this, however, the pressure increased up to $50 \mathrm{mmHg}$ in apparently normal cadavers and up to $100 \mathrm{mmHg}$ in the presence of the abnormality described by Osborne. It decreased by $50 \%$ after opening the osteofibrous canal. These data are compatible with those reported for carpal tunnel syn- 
drome (Kuhlmann, Tubiana and Lisfranc 1978; Gelberman et al 1981; Chaise and Witvoët 1984) and with experimental data on the effect of pressure on nerve conduction (Hargens et al 1979).

The major role of elbow flexion in the pathogenesis of ulnar nerve lesions was first proposed by Gowers in 1899. In a personal study of 312 patients with ulnar nerve lesions at the elbow (Seror 1992), I showed that twothirds of the symptomatic patients experienced their worst symptoms at night or in the morning on waking, and most of them reported sleeping with their elbows flexed. Postanaesthetic ulnar paralysis may well have the same cause, and ulnar palsies have been reported to develop in hemiplegic patients with hyperflexed elbows (Della Santa and Reust 1990).

There has been one previous report of a trial of treatment by splintage of the elbow in $45^{\circ}$ to $70^{\circ}$ flexion (Dimond and Lister 1985). In that series the overall result in 23 patients after a mean of 8.7 months was $86 \%$ improvement. This was compared with the $58 \%$ improvement obtained by surgical decompression by the same team over the same period in 31 patients. These results are similar to those in my series, where night splintage improved the symptoms in every case, even in the more severe palsies and after the failure of surgical decompression.

Four patients had very severe palsies. In the one case of tardy ulnar palsy, the hand had been wasted for a long time, and had recently become almost useless. Adoption of the splint enabled the patient to regain function in less than two months, although the hand later returned to its previous state. In two cases, the paralysis had developed after a deep sleep. Although recovery was incomplete, improvement was assessed to be $50 \%$ in one and $70 \%$ in the other. In the fourth case, a clinical cure was obtained after 15 days.

Three of my patients had undergone surgical decompression which was considered to have failed, both clinically and on the basis of the EMG findings two to six months after operation. Treatment by the night splint was effective in all three, with clinical improvement ranging from $60 \%$ to $95 \%$, and EMG improvement in two.

EMG monitoring was an essential element in this study. It showed the efficacy of treatment in all but one patient, and also that improvement was not due simply to transient local decongestion, as may result from hydrocortisone injection into the carpal tunnel (Seror 1989), but was associated with true restoration of nerve function. Recovery of sensory NCV was similar to that seen after decompression of the carpal tunnel (Seror 1989).

The sensory and motor NCVs were increased by an average of 9.5 and $6.5 \mathrm{~m} / \mathrm{s}\left(\mathrm{p}=10^{-8}\right)$ respectively after a mean follow-up of 11.3 months. This improvement implies local remyelination. The increased amplitude of the sensory action potentials and the improvement in the recordings indicated disappearance of the conduction block (Fig. 3) and regrowth of some axons. This improvement was also reflected in some cases by the resynchronisation of the SAP (Fig. 2).

The analysis of compliance was particularly interesting for the five patients in whom recovery was incomplete. The splint was used irregularly in four of them and one patient preferred to stop treatment after four months and opted for surgical treatment.

The advantage of prolonged treatment is suggested by the EMG results of one patient which showed, at two years, an improvement of three times that seen at six months. Another case showed the value of early treatment. When splintage was started less than three weeks after the onset of symptoms the quality and the rapidity of the recovery were remarkable, especially in view of the initial severity of the EMG signs (Figs 2, 3).

Conclusion. Prolonged flexion of the elbow by more than $90^{\circ}$ during sleep is an important cause of lesions of the ulnar nerve. The symptoms and the EMG signs can be rapidly and lastingly improved by the use of a night splint to prevent flexion beyond $60^{\circ}$. The splint should be worn all night continuously for six months.

The author chose not to respond to the request for a conflict of interest statement.

\section{BIBLIOGRAPHY}

Adelaar RS, Foster WC, McDowell C. The treatment of the cubital tunnel syndrome. J Hand Surg [Am] 1984; 9:90-5.

Amadio PC, Beckenbaugh RD. Entrapment of the ulnar nerve by the deep flexor-pronator aponeurosis. J Hand Surg 1986; 11-A :83-7.

Apfelberg DB, Larson SJ. Dynamic anatomy of the ulnar nerve at the elbow. Plast Reconstr Surg 1973; $51: 76-81$.

Brown WF, Ferguson GG, Jones MW, Yates SK. The location of conduction abnormalities in human entrapment neuropathies. Can J Neurol Sci 1976; 3:111-22.

de la Caffinière Y, Bex M. L 'épitrochléoplastie : un procédé de libération et de protection du nerf cubital au coude. Rev Chir Orthop 1983; $69: 649-51$.

Campbell WW, Sahni SK, Pridgeon RM, Riaz G, Leshner RT. Intraoperative electroneurography: management of ulnar neuropathy at the elbow. Muscle Nerve 1988; $11: 75-81$.

Chaise F, Witvoët J. Mesures des pressions intra canalaires dans le syndrome du canal carpien idiopathique non déficitaire. Rev Chir Orthop 1984; 70:75-8.

Chaise F, Bouchet T, Sedel L, Witvoet J. Résultats de la libération chirurgucale du nerf cubital dans les syndromes du défilé rétroépitrochléen. J Chir 1983; 120:251-5.

Dawson DM, Hallett M, Millender LH. Entrapment neuropathies. Boston etc: Little Brown Company, 1983.

De Jesus PV Jr, Steiner JR. Spontaneous recovery of ulnar neuropathy at the elbow. Electromyogr Clin Neurophysiol 1976; 16:239-48.

Della Santa DR, Reust P. Heterotopic ossification and ulnar nerve compression syndrome at the elbow: report of two cases. Sem HQp Paris 1990; 66:1653-6 [In French].

Dellon AL. Review of treatment results for ulnar nerve entrapment at the elbow. J Hand Surg 1989; 14-A :688-700.

Dimond ML, Lister GD. Cubital tunnel syndrome treated by long-arm splintage. $J$ Hand Surg 1985; 10-A :430.

Eaton RG, Crowe JF, Parkes JC. Anterior transposition of the ulnar nerve using a non-compressing fasciodermal sling. J Bone Joint Surg $[\mathrm{Am}] 1980 ; 62-\mathrm{A}: 820-5$.

Eisen A, Danon J. The mild cubital tunnel syndrome, its natural history and indications for surgical intervention. Neurology (Minneap) $1974 ; 24: 608-13$ 
Gelberman RH, Hergenroeder PT, Hargens AR, Lundborg GN, Akeson WH. The carpal tunnel syndrome: a study of carpal canal pressure. J Bone Joint Surg [Am] 1981 ; 63-A :380-3.

Gilliat RW, Thomas PK. Changes in nerve conduction with ulnar lesions at the elbow. J Neurol Neurosurg Psychiatry 1960;23: 312-20.

Gowers WR. A manual of diseases of the nervous system. Third ed, Vol. 1. Churchill: London, 1899.

Guegan Y, Pinel JF, Javaudin Y. Neurolyse du cubital au coude: à propos de 20 cas. Neurochirurgie 1982; $28: 127-9$.

Harding C, Halar E. Motor and sensory ulnar nerve conduction velocities: effect of elbow position. Arch Phys Med Rehabil 1983; 64:227-32.

Hargens AR, Romine JS, Sipe JC, et al. Peripheral nerve-conduction block by high muscle-compartment pressure. J Bone Joint Surg [Am] 1979;61-A:192-200.

Heithoff SJ, Millender LH, Nalebuff EA, Petruska AJ. Medial epicondylectomy for the treatment of ulnar nerve compression at the elbow. J Hand Surg 1990; 15-A :22-9.

Kuhlmann N, Tubiana R, Lisfranc R. Apport de l'anatomie dans la compréhension des syndromes de compression du canal carpien et des séquelles des interventions décompressives. Rev Chir Orthop $1978 ; 64: 59-70$

Latil F, Magalon G, Decaillet JM, Bureau H. Pathologie compressive du nerf cubital: à propos de trente-sept cas. Sem Hôp Paris 1982; 58:1113-7.

Lugnegard H, Walheim G, Wennberg A. Operative treatment of ulnar nerve neuropathy in the elbow region: a clinical and electrophysiological study. Acta Orthop Scand 1977; 48:168-76.

Lugnegard H, Juhlin L, Nilsson BY. Ulnar neuropathy at the elbow treated with decompression: a clinical and electrophysiological investigation. Scand J Plast Reconstr Surg 1982; 16:195-200.

Macnicol MF. Mechanics of the ulnar nerve at the elbow. $J$ Bone Joint Surg [Br] 1980; 62-B:531-2.

Mansat M, Bonnevialle P, Fine X, Guiraud B, Testut MF. Les paralysies cubitales tardives: etude d'une série de dix-sept cas. Sem Hôp Paris $1984 ; 60: 553-8$
Miller RG. AAEM case report 1. Ulnar neuropathy at the elbow Muscle Nerve 1991; 14:97-101.

Miller RG, Camp PE. Postoperative ulnar neuropathy. JAMA 1979; 242:1636-9

Nielsen VK, Osgaard O, Trojaborg W. Interfascicular neurolysis in chronic ulnar nerve lesions at the elbow: an electrophysiological study. J Neurol Neurosurg Psychiatry 1980; 43:272-80.

Omer GE Jr. Évaluation d'une lésion nerveuse périphérique posttraumatique. In: Monographie du Grange d'Etude de la Main no 10 Paris: Expansion Scientifique Ed, 1979:65-72.

Osborme GV. The surgical treatment of tardy ulnar neuritis. J Bone Joint Surg [Br] 1957; 39-B:782.

Seror P. Evaluation de l'efficacité du traitement infiltratif au cours du syndrome du canal carpien: donné es électrophysiologiques et applications cliniques. Revue du Rhumatisme 1989; 56:307-12.

Seror P. L'atteinte du nerf cubital au coude: données epidemiologique, clinique, électromyographique (à propos de 493 cas). Proc 16eme réunion de la sociéte d’électromyographique clinique de langue française, Blois, 1992.

Sindou M, Roussouly R, Mercatello A, et al. Syndrome canalaire du cubital au coude (49 cas): intérêt et dangers de la neurolyse microchirurgicale. Neurochirurgie 1982; 28:121-5.

Sunderland S. Nerves and nerve injuries. 2nd ed. Edinburgh, etc: Churchill Livingstone, 1978.

Tackmann W, Vogel P, Kaeser HE, Ettlin T. Sensitivity and localizing significance of motor and sensory electroneurographic parameters in the diagnosis of ulnar nerve lesions at the elbow: a reappraisal. $J$ Neurol 1984; 231 :204-11.

Thomsen PB. Compression neuritis of the ulnar nerve treated with simple decompression. Acta Orthop Scand 1977; 48:164-7.

Vanderpool DW, Chalmers J, Lamb DW, Whiston TB. Peripheral compression lesions of the ulnar nerve. J Bone Joint Surg [Br] 1968; 50-B:792-803.

Wilson DH, Krout R. Surgery of ulnar neuropathy at the elbow: 16 cases treated by decompression without transposition: technical note. J Neurosurg 1973; 38:780-5. 